\title{
LANGUAGE INSTRUCTION FOR NEWCOMERS TO CANADA (LINC): SUGGESTIONS FOR IMPROVEMENTS
}

$$
\text { by }
$$

Lindsay Baril, Hon. BA, University of Toronto, 2007

\author{
A Major Research Paper \\ Presented to Ryerson University \\ in partial fulfilment of the requirements for the degree of \\ Master of Arts \\ in the Program of \\ Immigration and Settlement Studies
}

Toronto, Ontario, Canada, 2011

CLindsay Baril 2011 
Author's Declaration

I hereby declare that I am the sole author of this major research paper.

I authorize Ryerson University to lend this paper to other institutions or individuals for the purpose of scholarly research.

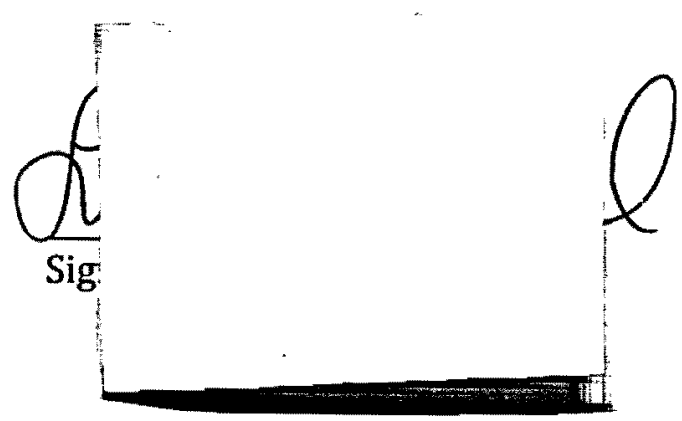

I further authorize Ryerson University to reproduce this paper by photocopying or by other means, in total or in part, at the request of other institutions or individuals for the purpose of scholarly research.

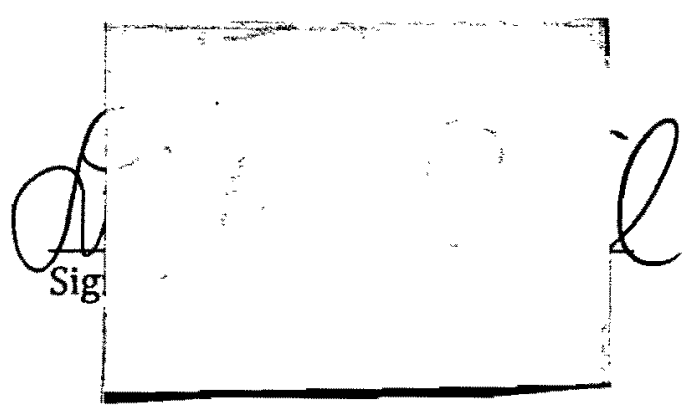




\title{
LANGUAGE INSTRUCTION FOR NEWCOMERS TO CANADA (LINC): SUGGESTIONS FOR IMPROVEMENTS
}

\author{
Lindsay Baril \\ Master of Arts, 2011 \\ Immigration and Settlement Studies \\ Ryerson University \\ 4 \\ ABSTRACT
}

Language Instruction for Newcomers to Canada (LINC) provides basic language instruction to adult newcomers in both official languages and facilitates the settlement and integration of immigrants and refugees into Canadian society. This study examined service provider organizations and the delivery of English language learning and assessment, and provides suggestions for improvements. LINC experiences are helpful as initial orientation to Canada and for learning English, but the program is limited in scope. Not only does the program delivery in terms of class times, schedules and availability, have limitations but assessment procedures, eligibility and teacher training are also in need of improvement. This critical examination provides ideas to guide LINC language learning delivery, assessment and efficiency in the future. It also makes use of intersectionality theory as a major avenue toward improvements.

Keywords: LINC; Service Provider Organizations; TESL Canada; Intersectionality Theory; Newcomers; Language acquisition 
Table of Contents

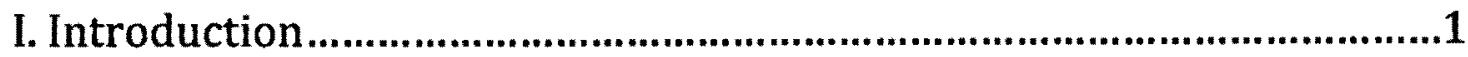

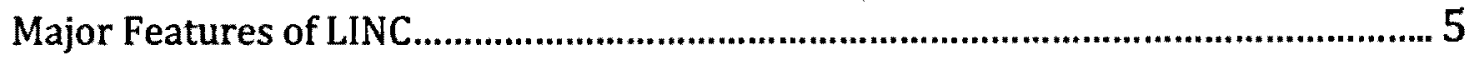

II. Research Questions and Research Methods.............................................8

III. Applying Intersectionality onto the TESL/LINC training field.............9

Social Determinants: Synergies of Oppression Framework........................................11

Possible uses of Intersectionality.........................................................................13

The intersectional composition of newcomers...........................................................18

IV. LINC: Time, Continuous Intake, Assessment \& Eligibility....................20

Time

Continuous Intake and Assessment........................................................................21

Eligibility..............................................................................................................2

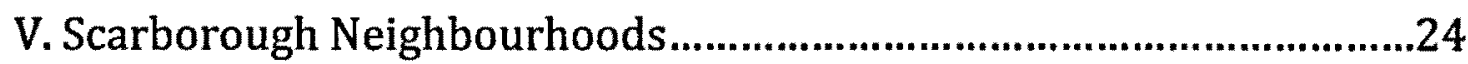

Outreach and Access to Information .............................................................................25

VI. Scarborough Service Provider Organizations (SPOs)......................... 29

VII. Discussion, Recommendations, and Conclusions...............................35

VIII. Appendix Table 1: Comparison of SPOs.............................................42

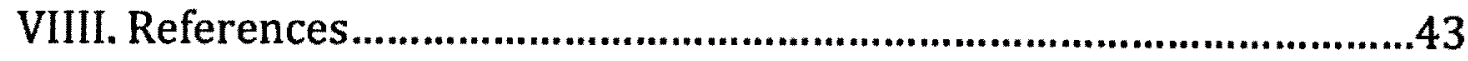




\section{Introduction}

The future success of Canada's immigration programs is strongly correlated with the ability of service provider organizations to deliver services to increasingly diverse populations to assist the integration of newcomers. Does language instruction and delivery efficiently facilitate newcomer's English language acquisition in Canadian society? This question forms a fundamental guide to view federal government language delivery and assessment policies. Moreover, this question may direct policy makers towards making changes to help improve the conditions of language instruction for newcomers in Canada.

In 1992, the federal government announced a new Federal Language Training Policy: Language Instruction for Newcomers (LINC). LINC is a training program accessed by a great number of non-English and non-French speaking immigrants. For the purpose of this discussion, I focus on the non-English speaking immigrant programs. The average annual number of clients in LINC training, in the years 2003-2008, was 67, 534 (CIC 2010).

Moreover, the average number of clients in training each year varies for each level but the largest number of newcomers is placed in LINC levels 2,3 , and 4 . There are now national operational guidelines to match LINC levels with Canadian Language Benchmark (CLB) levels. LINC level 2 is CLB 2, LINC level 3 is CLB 3,4 and LINC level 4 is CLB 4,5 (Canadian Language Benchmarks 2011).

The program is structured into levels of proficiency in English, with Literacy representing the most basic, limited proficiency in English and level 3, for example, a minimal communicative competence with simple interactions and texts in English 
(Hart \& Cumming 1997). Further, Ontario has the highest share of clients in training and for most LINC levels, Ontario's share accounts for nearly 85 percent of all clients (CIC 2010). Thus, Ontario service providers are leaders, innovators and unique, in Canada, in providing services that best serve newcomers.

LINC classes help learners develop and improve their listening, speaking, reading and writing skills. Classes are open to permanent residents of Canada, protected persons, persons in Canada applying to become a Permanent Resident and who have been informed, by letter, of the initial approval of the application, subject to an admissibility assessment. Further, convention refugees who are 18 years or older are eligible to take LINC classes. Finally, services are not open to Canadian citizens, refugee claimants or temporary residents (CIC 2011, TCDSB).

The 2003-2004 actual expenditure for the LINC settlement program in Canada was $\$ 92.7 \mathrm{M}, 52.2 \%$ of total integration spending. The total integration spending in $2003-2004$ was $\$ 176.6 \mathrm{M}$ (CIC 2010) compared to the $\$ 172.2$ million in 2008-2009. Even though spending appears to have increased over the years, the total integration spending in $2008-2009$ was $\$ 503.7$ million, $34.2 \%$ of total integration expenditures (CIC 2010). Thus, spending has decreased in percentage of total integration expenditures by $18 \%$ from 2003 to 2009 .

LINC is considered a national program, with the exception of British Columbia, Manitoba and Quebec, as these provinces signed agreements with the federal government to deliver their own settlement services. Funding is given to provinces to design, deliver and assess newcomers. In 2005, Ontario signed an agreement with the federal government to form The Canada-Ontario Immigration 
Agreement (COIA). In terms of language training, they agreed upon a four-year strategy for adult language training. The primary objectives were (1) to implement a language assessment system based on the Canadian Language Benchmarks (2) to establish a Working Group to identify emerging needs and service gaps (3) to establish the possibility of funding arrangements whereby Ontario coordinates the delivery of a portion of the Enhanced Language Training initiative in order to attempt to facilitate labour market integration (Ontario 2011). This agreement was important for serving the newcomer. However, the federal government did not give the province of Ontario the funding to deliver settlement services and the agreement is now on hold.

The following is a description of the delivery and assessment of LINC programs and LINC service providers. These descriptions lead to a discussion of inconsistencies in service, delivery and training. Program mandates and theory may sometimes be disconnected from program delivery and practice. This discussion provides useful information to help guide stakeholders in language training such as Ministry of Citizenship and Immigration: Language Training Unit, Citizenship and Immigration Canada, TESL Ontario, TESL Canada, Canadian Language Benchmarks, Public and Catholic School Boards and other Service Provider Organizations.

The LINC program is delivered by large public school boards, private language schools, community colleges, private trainers, community-based training programs and immigrant-serving agencies (Hart \& Cumming 1997). Thus, LINC cuts across a wide range of institutions and is viewed as involving more than just helping a newcomer improve their language skills but to "aid newcomers in adapting to, and 
understanding the values and customs of their adopted country, the way in which these new institutions work, as well as their rights and obligations" (Federal Immigrant Integration Strategy, quoted in Pinchero 1998:13).

Instructors in the federally funded program of Language Instruction for Newcomers to Canada (LINC) are responsible for teaching both the English language and citizenship values and concepts to adult immigrants. However, Derwing and Thompson (2005) surveyed teachers and program coordinators of LINC from Ontario, to determine to what degree they believe they are introducing citizenship concepts into the ESL classroom. Derwing and Thompson found that the federal government left the resolution of citizenship issues to LINC providers, including a number of concerns and questions such as what it means to be a Canadian citizen and questions such as: Are citizenship concepts and culture one and the same? (2005:4). Their survey was designed to ask respondents what resources were used in their programs to teach Canadian values. The most frequently cited materials were the daily newspaper ( $90 \%)$, commercially produced textbooks (87\%), Citizenship and Immigration publications (83\%), and printed handouts (83\%) (2005: 4-5).

However, after Derwing and Thompson examined the materials, they found little or no substantive Canadian-specific content and it was more North American in nature (2005:9). Finally, with regard to citizenship concepts, $96 \%$ of respondents reported they utilize real-life examples to introduce citizenship issues, such as fieldtrips to citizenship ceremonies, the police station and the city hall $(2005: 10)$. 
In a similar vein, James (2000) found that none of the cultural items in the LINC curriculum in Ontario mentioned values or beliefs. Rather, he concluded that most were focused on superficial cultural differences. Thus, the federal mandate to help teach newcomers Canadian values was not delivering the promised services to best suit newcomers needs.

However, there have been several changes in the past year in terms of LINC program delivery. In January 2011, a Discover Canada booklet, a study guide for newcomers and training manual for instructors, was released by CIC for service providers (CIC 2009). The study guide includes seven chapters: (1) Rights and Responsibilities of Citizenship (2) Who we are: Aboriginal peoples, English and French, and Diversity in Canada (3) Canada's History (4) Modern Canada (5) How Canadians Govern Themselves (6) Federal Elections and (7) The Justice System. The study guide also includes information on Canadian symbols, economy and regions. This aspect of language training makes LINC a unique program but it is still the responsibility of the service providers to deliver the study guide material. An interesting area of research would be to analyze the content distributed by CIC to compare and contrast the differences between what James (2000) described as superficial cultural differences and what CIC has distributed this year. This area of investigation is important because it would highlight that program mandates and theory may sometimes be disconnected from program delivery and practice. Major Features of LINC According to CIC (2010), the LINC program involves three major areas of activity. First, the Canadian Language Benchmarks framework is used for language 
assessment in order to determine a newcomer's level of proficiency. Citizenship and Immigration Canada define a benchmark as a standard, a reference point by which to measure something (CIC 2010). A Canadian Language Benchmark for English as a Second Language is a description of a learner's ability to use the English language to accomplish a set of tasks. Without a standard it is difficult to measure language acquisition. Further, "language benchmarks provide learners with what they have yet to learn and what they have learned. Not only do the benchmarks provide a common basis for assessment of both learners and institutions offering English as a Second Language (ESL) classes, they also describe ability within a specific area of language skill" (CIC 2010). There are four skill areas: listening, speaking, reading and writing and twelve benchmarks in each area (CIC 2010).

Second, language training is provided depending upon each client's language abilities and each newcomer is assessed before they begin classes. Referral services engage in considerable outreach to newcomers. For example, the Young Men's Christian Association (YMCA) Language Assessment and Referral Centre participates in outreach to newcomers using pamphlets at airports, service providers with LINC classes, word of mouth and the internet such as the CIC website and settlement agencies (YMCA 2011). After newcomers find out about the process they can call the centre to book an appointment. In Scarborough, YMCA also has the contract for language assessment and referrals. The referral service suggests a proper placement service provider and proper enrollment level according to needs, transportation, and area of living. Specifically, in Scarborough, the Young Men's Christian Association (YMCA) is responsible for language assessment and placing 
learners into SPOs. The YMCA states that since 1992, all three YMCAs in the Toronto area, including Scarborough, have assessed approximately 230,000 newcomers (YMCA 2011). The assessment stage is the first step in finding a service provider for LINC language acquisition in Scarborough.

This process is as follows: First, the assessor screens for eligibility to take LINC classes and fills out an intake form and needs assessment. The newcomer then has a listening and speaking interview involving interactive audio and video. The next phase is a reading and writing test. After results have been recorded in the History of Assessments, Referrals and Training System (HARTs) database, the learner is given a client profile with their Canadian Language Benchmark results in all four areas. $\mathrm{CIC}$ has a national placement grid that matches Canadian Language Benchmarks with LINC language levels. Finally, newcomers are given placement options depending on needs. This process is unique for every individual because it depends on language learning goals and needs, desired travel time, child-care needs, availability and wait lists (YMCA 2011).

Third, the Federal government assists with funding to improve the delivery of LINC programs for the direct benefit of clients. For example, funding is used toward research and innovation: development of training materials, training for assessors and analysis of training needs. This funding goes to, among others, Teachers of English as a Second Language (TESL) to provide materials and training; to YMCA in Scarborough for assessment training; and research analysts working for the government (CIC 2010). 
An overview of the LINC program led to three important questions central to this discussion: [1] To what extent is the delivery of the program appropriate and are there more effective delivery methods that could be considered? For example, LINC is almost entirely a classroom-based program and approximately $95 \%$ of LINC students attend classes (CIC 2010). (2) To what extent do settlement services that offer LINC, involve the most appropriate, efficient and cost-effective methods to meet their objectives? For example, existing program evaluations focus on LINC delivery in Canada but I would like to evaluate inconsistencies in what is being reported and what is actually happening based on Service Provider Organizations in Scarborough (3) Are there additional language services that could be integrated into the LINC program to assist the integration of newcomers?

\section{Research Methods}

The above features and questions were addressed using the following research methods, which have three components:

(1) Applying Intersectionality Theory and TESL Program Analysis:

This analysis identified TESL Diploma programs that met the following criteria: (a) Offered Standard Two TESL Diploma Certificate Programs; and (b) offered training programs in the City of Toronto. This research aimed to critically analyze whether or not theoretical courses, anti-discrimination courses, inequality courses, or courses on the cultural background of newcomers were included, and if these were mandatory from a perspective that consider the intersections of being a newcomer, difficulties in language acquisition and barriers to continuous learning.

(2) LINC Program Review: 
This review focused on LINC language training programs, assessment practices, program delivery and efficiency. The review focused on academic literature, Citizenship and Immigration Canada (CIC) evaluations and the Report to the Ontario Region LINC Advisory Committee. The review also focused on best practices found in other language class delivery such as the Adult non-credit ESL program offered by the province of Ontario.

(3) Scarborough Neighbourhood and Service Provider Analysis:

Research focused on the Scarborough area with regard to specific neighbourhood language, ethnicity and immigration profiles. This research also focused on LINC language service providers in three Scarborough neighbourhoods. I analysed daily class schedules, class times, availability and services provided at each location according to their individual websites. This analysis provides information for service providers to be able to better understand newcomer needs, cultural backgrounds and cultural differences. It is also useful for LINC program evaluations and considerations. A closer look at Service Provider Organizations could help develop an understanding of the unique qualities and specific needs of Ontario language programs.

\section{Applying Intersectionality onto the TESL/LINC training field}

In recent years, the concept of intersectionality has emerged from feminist studies and has been widely used and discussed (Crenshaw 1989, Collins 2005). However, intersectionality implies more than gender research; it focuses on diverse and marginalized positions (Knudsen 2006). Kimberle Crenshaw coined the concept of intersectionality in the late 1980s (Davis 2008:68); she claims that intersectionality 
attempts to mediate the relationships among socio-cultural categories and identities (Crenshaw 1993: 114). In addition, Knudsen points out that gender, race, ethnicity, socio-economic class, nationality, immigrant status and age are examples of categories that may enhance the complexity of intersectionality and point towards identities in transition (Knudsen 2006:1).

It is now recognized that people are not one-dimensional; they position themselves in multiple identities. There is a need for theories that deal succinctly with the complexities of being a human being (Knudsen 2006). Intersectionality emphasizes the importance of context. For example, the compounding effects of lack of access to education and lack of quality of language acquisition services could create implications for income and employment for newcomers. Wilkinson (2003) furthers this discussion by adding that a key problem in Canada is that programs and policies do not often reflect the lived experience of Canadians and that individuals with many different intersecting identities should be considered when programs are designed. For example, a newcomer to Canada has an identity in transition in terms of immigration status, immigrant category, place of birth, socioeconomic status and employment/unemployment.

Intersectionality theory when put into practice could be used to train language instructors to consider the spectrum of intersections newcomers face during settlement and integration in Canada. There is a need for this application because having knowledge about learner's backgrounds, ethnicity, history and difficulties involved in attempting to integrate in a new society will lead to a better understanding of newcomers and the potential marginalized positions they 
encompass. How can we implement Intersectionality theory into Teaching English as a Second Language (TESL) training and practices?

Social Determinants: Synergies of Oppression Framework

Social determinants of language acquisition play a role in shaping newcomers' outcomes and abilities. Intersectionality frameworks emphasize "an understanding of the many circumstances that combine with discriminatory social practices to produce and sustain inequity and exclusion..."(Canadian Research Institute for the Advancement of Women 2006:7). For example, McGibbon and Etowa (2007) introduced a framework for addressing inequalities: synergies of oppression. They demonstrate how oppressions operate in a synergistic manner. Further, they consider how three areas (Intersections of Social Determinants, Intersections of Identity and Intersections of Geography) intersect with each other.

For my purposes here I would like to use McGibbon and Etowa's (2007) framework and apply it to language acquisition for newcomers. First, examples of social determinants of language acquisition include: income, education, unemployment/employment, food insecurity, social exclusion and social safety networks. Second, examples of intersections of identity include: age, culture, ethnicity, caretaker, parent and immigrant status. Third, examples of social determinants of language acquisition and geography include: rural/urban living arrangements, segregation, ghettoization, unfair geographic access to services, and lack of access to public transportation. Thus, for example, lack of education operates in synergy with unemployment and underemployment, which in turn increase the likelihood of food and housing insecurity (McPherson and McGibbon 2010). 
In 1995, Citizenship and Immigration Canada, in conjunction with the Ontario Region LINC Advisory Committee (ORLAC), contracted with a research team at the Ontario Institute for Studies in Education (OISE) to conduct a follow-up survey of graduates of the LINC program who have completed LINC level 3. This study was conducted with a sample of 900 graduates in six language groups: Arabic, Cantonese, Polish, Spanish, Somali and Tamil. The value of the study, according to Hart and Cumming, the primary researchers, is descriptive, documenting what people who have completed LINC level 3 have done, and not done, after completing the program (Hart and Cumming 1997:2).

Hart and Cumming 's findings in the follow-up study, of people in Ontario, completing level 3 of the (LINC) program can also be applied to the synergies of oppression framework. Respondents to the in-depth interviews found that in order to be able to find meaningful employment, they need to learn considerably more English (1997:82). They also perceived the lack of English proficiency to be constraining their uses of English in their daily lives, particularly to obtain government and health services and their opportunities for further education and work (Hart and Cumming 1997:82). "Nearly every respondent, 900 were surveyed, cited their limited English as the major constraining factor limiting their opportunities to pursue further education" and "some also mentioned their family responsibilities or lack of money, time away from work, or transportation as constraints on their taking courses"(Hart and Cumming 1997:85-86). Further, "virtually every respondent observed how their limited English constrained the work opportunities they could seek" (Hart and Cumming 1997:87). And finally, 
respondents clearly stated that LINC only provided them with a basic facility in English and orientation to Canada. One respondent explained: "LINC being helpful to me? I can tell you one thing. You learn a little English so that when you are on the street and someone asks you a question, you can give an answer. But then if the talk develops, you are stuck" (Hart and Cumming 1997:91). Another respondent stressed: "I lack confidence because of my weak English. I need to improve my English to become more confident" (Hart and Cumming 1997: 87).

The concept of synergy provides a useful way to grasp the complexity of the social impacts of all of these intersections. For example, contexts of oppression such as lack of English proficiency are further compounded by lack of meaningful employment, lack of self-confidence, lack of ability to communicate properly and lack of ability to pursue further education. Thus, these oppressions operate in a synergistic manner and increase the likelihood of food and housing insecurity and ultimately increase inequities.

Possible uses of Intersectionality

To illustrate possible uses of intersectionality in instructor training, I draw attention to TESL certificate and diploma programs in Toronto. TESL Canada's mission is to promote excellence in the teaching and learning of English as a second or additional language in partnership with its constituent provincial and territorial associations, and like-minded national and international organizations (TESL 2011).

In addition, TESL Canada values include: "excellence in language, settlement, and refugee programs; national standards for professional certification and teacher training program recognition; working together with provincial and territorial 
associations on common goals; promoting ongoing professional development; research and scholarship in the field of teaching and learning ESL; linguistic rights for individuals and communities; equality of employment opportunity for qualified non-native English-speaking and native English-speaking teachers and assisting with English language development while still protecting Ancestral languages for speakers of Indigenous first languages" (TESL 2011).

TESL has national standards for professional certification. However, an analysis of mandatory courses for TESL instructors shows that 'intersectionality' is a concept absent in the training field and I will demonstrate this in the sections to follow. In addition, I will examine the possibility of a lack of quality measures and standards for trainers and participants of diversity training.

Baer et al. (2009) stress the importance of intersectionality in training by referring to gender training. I use their analysis as a framework and apply it to TESL instructor diversity training. Baer et al. use the term "intersectionality" and make it relevant with regard to three different aspects. First, the term is used to name the relation between different inequalities. For example, it could be assumed that if you understand gender inequality it can be transferred to other forms of inequality but this would imply that all inequalities are the same and that would be an improper assumption (2009:13). There is a wide spectrum of inequalities that do not fit into a gender inequality framework such as discrimination against a lack of Canadian work experience, discrimination against accents, sexual orientations, cultural or religious practices and being a visible minority, to name a few.

Second, the term is used as an analytical perspective, an approach that 
identifies the characteristics that may be grounds for unequal treatment by others. For example, this approach allows instructors to recognize intersectional compositions of the group of participants and also intersectional compositions of themselves. Instructors are encouraged to consider their own position and aspects they may take for granted in order to better recognize that newcomers have their own unique position, taking certain aspects for granted as well.

Third, Baer et al. use the term 'intersectionality' to refer to an ongoing discussion of how to conceptualize and analyze overlapping inequalities, multiple discriminations and intersecting categories (2009:6). In other words, encouraging an open mind to new possibilities, opinions, circumstances and difficulties.

For the purpose of this discussion, I analyzed several TESL diploma programs and their requirements. I was interested in what types of training there are, or if there is a standardized training in Ontario with respect to discrimination, inequality, anti-discrimination, sensitivities to other cultures, different cultural backgrounds, and the intersections of these topics.

My main focus was on courses required to complete the TESL Professional Certificate Standard Two Program. To obtain the title: Professional Standard Two (Interim) Instructor, you are required to have a University degree plus 250 hours of TESL methodology and theory and a minimum of 20 hours in a supervised adult ESL/EFL classroom practicum. You become a Professional Standard Two (Permanent) after 1500 hours of teaching experience.

TESL Canada national standards provide "a national focus for all ESL educators and encourage high levels of participation in an accreditation system that 
recognizes and values the diversity of approach to ESL instruction in its many settings. Since their implementation in May 2002, the TESL Canada National Professional Certification Standards are continuing to be the authoritative base for evaluation and comparison of ESL teacher training in Canada" (TESL 2011).

In Toronto, there are four institutions that offer this program: Canadian Centre for Language \& Cultural Studies (CCLCS) which is a Non-Government Organization (NGO), George Brown College of Applied Arts \& Technology, Humber Institute of Technology and Advanced Learning, and University of Toronto/Woodsworth College. After an analysis of the required course descriptions pertaining to the topics mentioned above, I discovered a list of titles that each institute uses to teach TESL instructors these concepts.

My analysis identified varying requirements within the four institutions. For example, CCLCS requires instructors to take a five hour anti-discrimination workshop: Anti-Discrimination Pedagogy. It is available to take on a Saturday and is mandatory (CCLCS 2011). George Brown requires their instructors to take a mandatory course: TESL Methodology (TETR4000). There are fourteen topics covered in this course, two of which are cultural pluralism in Canadian society, and possible barriers to second language speaker's participation in Canadian society (George Brown 2011). Humber requires instructors to take two half-credit courses titled: The Adult ESL Learner I and II, which touch on different backgrounds of the adult learner (Humber 2011) and University of Toronto: Woodsworth College requires instructors to take a half course: Theoretical Issues in Second language Teaching and Learning (TSL561H1). The focus of this half-credit is on the cognitive 
and socio-cultural factors that most affect adult language learners and the resultant implications for the classroom (Woodsworth 2011). Consequently, the relevant focus is one of five focuses for the half-course required. Thus, it is very limited in time and scope of materials.

These course descriptions highlight the variety of course requirements, lengths, concepts and understandings of equality and diversity training and demonstrates that there is no standardized required course dealing with the intersections of inequality, synergies of oppression, backgrounds and history of students, diversity or anti-discrimination. One could infer that having a better understanding of the newcomer in terms of the various positions they encompass could improve the overall teaching and learning experience. Thus, it could be recommended that TESL implement a standard course or courses to teach instructors in-depth information about learners: backgrounds, needs, the importance of language learning in the Canadian context, how to help overcome barriers, the importance of sensitivity, the effects of culture shock, cultural differences and understandings, and how the instructor is positioned in this environment.

According to CIC, nearly $85 \%$ of LINC teachers surveyed for the evaluation of the LINC program had a TESL diploma (CIC 2010). This is a very important finding for this discussion. If there were a standardized required course for TESL diploma instructors, it would encourage a national standard, for diversity training for LINC instructors. This recommendation could encourage discussion regarding intersectionality. It could also develop an awareness of the intersectional 
composition of the participating group and the teacher's ability to address it appropriately. Thus, according to Baer et al., training on equality issues can be seen as a route to transfer theory into practice (2009: 19).

They also suggest that instructor training should include ways in which the instructor can apply an intersectional perspective. For example, Baer et al. suggest that instructors need competence in relation to four aspects: willingness, knowledge, skills and power (WKSP) (2009:19). By willingness, they mean a motivation to work towards the goal of transformative equality policies. By knowledge, they refer to the instructor's familiarity with a broad spectrum of intersectionality theories and the instructor's needs to be able to distinguish between and among different conceptualizations. Skills refer to a range of soft skills such as awareness of the intersectional composition of the newcomer participants and the ability to address this composition, as well as mediating skills and conflict management. Finally, power refers to the standing of instructors and how service providers train their staff. It depends on the flexibility instructors are given in their approach to teaching (2009:19).

The intersectional composition of newcomers Ontario's percentage of all Canadian LINC clients is $82.4 \%$, the LINC population is also dominated by females, accounting for almost three-quarters of clients (CIC 2008). CIC survey data show that LINC students originate from all parts of the world, 81 different countries in all. China is the nation of origin of the largest percent of LINC learners at 22\% in Canada and 25-30 percent of clients in Ontario. The next largest country of origin in Canada, is India, the birthplace of $8 \%$ of the 
students; and Iran, Pakistan, Afghanistan and Sri Lanka each account for approximately 5 percent of the clients in Canada each year (CIC 2010)

It is also important to note that LINC clients have different immigration categories, which are an additional consideration in the intersectional composition. For example, in 2008, there were 12,948 clients in LINC level 2 training in Canada and 10,295 in Ontario. If we break down these numbers in terms of immigration categories in Canada, 5,455 were from family class, 2,371 were skilled workers, 1,002 were "other economic", 3,737 were refugees, and 383 were under the "Other/Unknown" category (CIC 2010).

Taking this information into account, TESL instructor training could locate intersectionality within an anti-discrimination framework in conjunction with important contextual aspects such as citizenship, social class, immigrant category and marital status and the composition of newcomers to Ontario. However, the context would shift in different classroom settings and the contextual aspects would have to consider a wide spectrum of overlapping and intersecting categories. Thus, I recommend this type of training be implemented in all TESL certificate training and that there be a nationwide standardized mandatory intersectionality course for all TESL instructors. LINC instructors spend a considerable amount of time with learners, approximately 300 hours per level, or 4 hours per day 5 days a week for a full-time learner, making instructors very important contact individuals for LINC learners. Because of this, it is crucial for LINC instructors to have training to develop a better understanding of the backgrounds, context, living environments, family and employment/unemployment pressures that intersect for newcomers to 
Canada. In sum, for a successful inclusion of intersectionality into TESL training, instructors need to be aware of how newcomers are located in intersectional positions. With better understanding and knowledge comes a better learning and teaching environment for both instructors and newcomers.

\section{LINC: Time, Continuous Intake, Assessment \& Eligibility}

There are multiple barriers inhibiting newcomers from learning to their capacity in programs such as LINC. These include: lack of access to information, ineligibility, the nature and size the classroom, lack of standardized performance assessment, language learning time, lack of daycare services or wait-lists for these services and continuous intake. For my purposes here, the language learning time, continuous intake, lack of standardized performance assessment and ineligibility are particularly important and will be my focus.

Time

There are several aspects to consider: First, classes are linguistically and culturally diverse with respect to learners and they have individual language learning needs and difficulties. To address these needs, a language instructor needs time (CIC 2008). However, most learners do not have an unlimited amount of time to take English classes. Classes are only offered at certain times during the day and clients have other time-constraining responsibilities such as employment, searching for employment, and family responsibilities to name a few. According to performance results provided by Citizenship and Immigration Canada (2008), the average amount of time taken to complete LINC level 1 is 379 hours, LINC level 2 is 368 and LINC level 3 is 337 . Thus, it takes an average of 1,084 hours to complete levels 1-3. 
Further, it takes on average 309 hours to complete level 4. The same Citizenship and Immigration Canada analysis also reveals that the largest numbers of clients in training are found in LINC levels 2 and 3. One can infer and calculate from this information that it takes a minimum of 28 hours per week for 52 weeks (one year), considered full-time, to finish LINC levels 1-4. This does not include travel time to and from the service provider location.

\section{Continuous Intake}

Second, classes are often characterized by continuous intake, which means further difficulty in language acquisition (Pinchero 1998:15). Continuous intake, in this context, means new learners starting at different times and at various stages in the same level. CIC argues that this could be positive because clients do not have to wait (2010), however, this issue needs to be addressed because it may be more beneficial for students to wait (Pinchero 1998) for the next level to begin rather than begin with students who have already covered the material they intend to or need to cover. Continuous intake means that each student starts with a different foundation than the next student. One can infer from this that continuous intake makes it difficult for instructors to build on yesterday's lessons, to bring up examples from the past or use a similar role play or type of instruction without having to explain aspects, materials and examples from the beginning.

\section{Assessment}

Third, there is nothing in place, such as level tests or exams, for newcomers to set goals, after their initial assessment. The current situation at LINC regarding assessment is as follows: LINC assessment centres deliver standardized, Canadian 
Language Benchmark (CLB) based placement tests. There are four separate benchmarks that students are given, one each for reading, writing, listening and speaking. The learner is placed in the LINC level that matches the lowest CLB level. In terms of assessment after a newcomer begins language courses, there is no standardized system for performance measurement data. Further, in terms of outcomes, there is no standardized outcomes test. [Saint Germain 2009). The purpose of measurement is not only to motivate and empower students but also to contribute to a standard curriculum and an outcome test over time would contribute to labour market success in terms of "credentializing" (Saint Germain 2009). In sum, there is a need to address placement assessor credentials and ongoing assessment to motivate students, and to put in place a standardized outcomes test for LINC learners. These additions would not only contribute to a standard curriculum but also empower students. Further, an ongoing assessment based on CLB would give learners an idea of what they have accomplished and what they need to accomplish by Canadian standards. Finally, an outcomes test would provide proof of language proficiency at a certain level. This test could become a goal for language learners and would be valuable on a resume if the learner needs language proficiency to enhance career choices and opportunities (Saint Germain 2009). It is important to stress here that I am suggesting that we give learners the option to take these tests. Not all learners want to test themselves in this manner because learners have different needs and goals; however, it would be a positive reinforcement for those who do wish to improve their language proficiency for the 
workforce or simply to take these tests to set and reach personal or professional goals.

\section{Eligibility}

In terms of eligibility, the term 'newcomers' in Ontario does not mean all newcomers. Even though LINC is mandated to provide basic language instruction to adult newcomers, temporary residents are not eligible for LINC. According to research published by the Ontario provincial government, in 2006 there were 240,264 temporary residents in Ontario. The categories of temporary residents include: foreign workers (38\%), foreign students ( $27.4 \%)$, humanitarian entrants including refugee claimants (24\%) and 'other' temporary residents (10.6\%) (Ontario 2011). One interesting point to make here is that 21,047 of temporary residents are live-in caregivers, primarily women who are caring for children, the elderly or people with disabilities in Ontario (Ontario 2011). If language-training classes are a primary means of accessing information, a means of building social networks and social support to decrease the challenges of adapting to a new country and culture, why are we leaving out the 21,047 newcomers who are living here to take care of our young and vulnerable populations? Further, one section of the Federal LINC program mandate is to facilitate the settlement and integration of immigrants into Canadian society. If we are discounting hundreds of thousands of newcomers for eligibility for LINC, we are not facilitating those needs.

Moreover, current LINC eligibility criteria exclude Canadian citizens. Thus, learners who become Canadian citizens must then switch to a different program, most often in a different location. Thus, a learner would have to stop LINC lessons 
with LINC curriculum guidelines. These guidelines are intended to establish measurable outcomes so that standards in the LINC program are consistent. However, the standards are not consistent when newcomers are no longer eligible for LINC. Further, LINC does not have a standard exiting assessment, leaving learners with nothing to bring to another service provider in terms of needs, progress and achievement.

After leaving LINC classes, the learner would have to attempt to find an alternative English language class, have a second assessment, possibly be put on a wait list for another program and have to pay for language lessons. As mentioned above if it takes a part-time learner over four years to finish four levels, a newcomer who becomes a Canadian citizen would not even have the opportunity to finish three LINC levels. This is assuming that the newcomer found out about LINC when they first arrived in Canada. If a newcomer found out about LINC after a year of living in Canada, for example, and it takes approximately three years to become a Canadian citizen, this leaves even less time for LINC language learning. In sum, I recommend that eligibility criteria based on immigration status should be eliminated in the LINC program.

\section{Scarborough Neighbourhoods}

Since the municipal amalgamation in 1998, Scarborough is now considered to be part of the City of Toronto in terms of data collection and the census. However, Scarborough is a unique and important area in terms of immigration in Canada. In 2006 , Scarborough's population was 602,575 . A study based on census data 
between 1996 and 2001 shows that Scarborough's growth rate was more than 6\%, the highest growth in Toronto. A significant portion of Scarborough's population is composed of first and second generation immigrants who have arrived in the last four decades. In $2006,57 \%$ of residents were foreign born. Visible minorities make up $67.4 \%$ of the population. South Asian residents make up $22.0 \%$ of the population, and Chinese residents account for $19.5 \%$ of the population, Black Canadian residents make up $10.3 \%$ of the population, while Filipino residents account for $6.5 \%$ (Statistics Canada 2007).

\section{Outreach and Access to Information}

As seen from the diversity of origins of immigrants, they are not a single group with needs that can be met by a single assessment, program or instructor. Scarborough has twenty-two different neighbourhoods with immigrants with varying needs-not just between neighbourhoods but within neighbourhoods as well. However, for the purpose of this discussion, I want to focus on the language and ethnicity profiles in certain areas in Scarborough and how they differ between neighbourhoods. These profiles were prepared by the Social Policy Analysis and Research Unit in the Social Development \& Administration Division with assistance from Toronto Public Health (Statistics Canada 2006). By determining ethnic background, language in the home and immigration trends in neighbourhoods it could be helpful for agencies to reach out to newcomers more effectively, help newcomers access information and help agencies train instructors on cultural sensitivities.

Further, ethnicity and language profiles are important because they could be used to help government, community and schools with planning by providing socio-cultural 
data of a geographic area. Neighbourhoods are defined based on Statistics Canada census tracts. Census tracts include several city blocks and have on average 4,000 people (Statistics Canada 2006). The boundaries for the neighbourhoods were developed using the following criteria: (1) Originally based on an Urban Development Services Residential Communities map, (2) Based on planning areas in former municipalities, (3) Existing Public Health neighbourhood planning areas (4) No neighbourhood is comprised of a single census tract and (5) The minimum neighbourhood population is $7-10,000$ (Statistics Canada 2006).

Important for this discussion is the language that new immigrants speak in their home, the ethnic origin of people in specific neighbourhoods and the percentage of immigrants and recent immigrants in certain neighbourhoods. Specifically, I will discuss the social profiles of three Scarborough neighbourhoods: Milliken (North-Central Scarbourough), L'Amoreaux (North-West Scarbourough) and Wexford/Maryvale (North Scarbourough). I chose these three areas because the service providers I discuss in the next section are located in one of these neighbourhoods. The Polycultural Immigrant \& Community Services has a service location in Milliken. The Mennonite New Life Centre has a centre in L'Amoreaux and one of the Toronto Catholic District School Board TCDSB service provider locations, Maryvale, is in Wexford/Maryvale. These statistics are very useful for three reasons: (1) They provide government policy makers, local service providers and TESL program developers with percentage information regarding ethnic origins (ancestry) in neighbourhoods. (2) They provide statistics regarding native languages. (3) They provide information regarding immigration percentage compared to all of Toronto and percentage of recent immigrants in specific neighbourhoods. 
First, they provide government policy makers, local service providers and TESL program developers with percentage information regarding ethnic origins (ancestry) in neighbourhoods. This could be helpful in terms of outreach and how to provide information to communities. For example, Milliken has 17,120 residents who self identify as having Chinese ethnicity, 2,225 residents who have self-identified as East Indian and 425 Tamil residents (Statistics Canada 2006). By comparison, Wexdale/Maryvale has 2,115 residents who self identify as having Chinese ethnicity, 2,850 Filipino residents and 1,435 East Indians. One can infer from this information that outreach in these neighbourhoods could use different avenues and strategies. Hart and Cumming (1997) found, in their study, that one barrier to learning English was lack of access to information regarding how to find information about language programs and where service providers and assessment agencies are located. The purpose of considering ethnic origins in neighbourhoods is not to exclude but to include.

Second, they provide statistics regarding native languages. In Milliken, in 2001, the total population having no knowledge of official languages was 14.3 percent. By comparison, in 2006, the percentage of people having no knowledge of either English or French increased to 17.2 percent. This statistic has increased by 2.9 percent over five years. This leads to two important questions: (1) How do service providers increase access to information regarding language classes? (2) How do service providers deliver needs assessment in neighbourhoods where we witness this sort of decline? What we know is that in a five-year period there is not much change in terms of the top five languages in the home. For example, in Milliken, in 2006, the top five languages immigrants spoke in the home besides English and French were Chinese, Tamil, Tagalog 
(Filipino), Urdu and Gujarati. Five years prior, the top five were Chinese, Tamil, Punjabi, Urdu and Tagalog.

In addition, in L'Amoreaux in 2001, the top five languages were Chinese, Tamil, Armenian, Persian (Farsi) and Italian. The Chinese population was 27.7 percent of visible minorities. In 2006, the top four languages were the same with the exception of Tagalog becoming number five. One noticeable difference is that 35.9 percent of the population in 2006 was Chinese; a considerable increase from 2001. Moreover, the percentage of residents with no knowledge of English or French was 9.1 in 2001 compared to 11.3 percent in 2006. What we can infer from this is that neighbourhoods are not static and needs may change over time as residents age, move and have families. In Wexford/Maryvale, the top five home languages besides English and French were: Chinese, Tamil, Tagalog, Urdu and Arabic. In 2006, the languages were Tagalog, Chinese, Tamil, Greek and Italian. Finally, in Wexford/Maryvale, the percentage of residents with no knowledge of an official language in 2001 was 3.1 percent compared to 2.9 percent in 2006. This leads to an important question: Why is this information useful?

First, Chinese, Filipino and Tamil language needs and difficulties could be addressed and considered before an instructor begins to teach in Wexdale/Maryvale with Service Provider Organization (SPO) training or TESL training or both. Language learners from different backgrounds have specific language difficulties such as unique pronunciation problems and difficulties articulating certain sounds when learning English (Meyers 1993). This information could be helpful to design special interest, needs and pronunciation workshops at individual service provider locations.

Second, having information regarding languages in the home may provide 
information to primary and elementary schools on how to outreach to parents and families regarding the importance of English language learning for parents and grandparents. According to Hart and Cumming (1997) one of the top priorities and needs for language learners is being able to properly communicate with teachers and administrators at their children's schools in conjunction with being able to communicate with their children in English.

Third, they provide information regarding immigration percentages compared to all of Toronto and percentages of recent immigrants in specific neighbourhoods. After the amalgamation of Scarborough into the City of Toronto it is difficult to demonstrate that neighbourhoods in Scarborough have varying needs. For example, in Milliken the percentage of immigrants in 2001 was 73.6 percent and percentage of recent immigrants was 15.1 percent. By comparison, and to highlight changes in neighbourhood immigration trends, in 2006, recent immigrants percentage decreased to 13 percent, however the percentage of immigrants remained the same (Statistics Canada 2006). Finally, this information is important in terms of where funding is allocated for language learning purposes.

\section{Scarborough Service Provider Organizations [SPOs]}

In Ontario, local institutions, agencies, or jurisdictions like school boards or colleges typically have responsibilities for implementing language assessment for LINC; these are called service provider organizations (SPOs) (Cumming 1994:118). There are several language service provider options for newcomers. According to Findhelp Information Services (2011) there are twelve LINC service provider organizations in Scarborough. Five of these providers have more than one location. There are 
eighteen LINC locations in Scarborough. Consequently, many of these service providers target, directly or indirectly, very specific cultural/religious beliefs language learners. For example, service providers in Scarborough include: Tamil Eelam Society of Canada, Mennonite New Life Centre, Afghan Women's Organization, Toronto Catholic District School Board and Catholic Cross-cultural Services. Thus, there are six service providers in Scarborough that do not have inclusionary names. For example, having the word Catholic or Mennonite in a service provider's name could be confusing, uncomfortable or misleading for newcomers with different religious belief backgrounds.

The other six service providers appear to have more cross-cultural names; at least in terms of the names of the service providers. For example: Canadian Centre for Language and Cultural Studies, Centennial College School of Advancement, Centre for Information and Community Services of Ontario, Cross-Cultural Community Services Association, Polycultural Immigrant \& Community Services and Settlement Assistance \& Family Support Services. For the purpose of this paper, I will discuss three of these service providers, what they provide and how appropriate their delivery is for language learners. The reason I chose these three is because they are examples of large: TCDSB, medium: Polycultural and small: Mennonite, service providers in terms of the total number of classes offered on a weekly basis. In addition, TCDSB plays a role in writing LINC curriculum. Thus, in the next section, I will investigate how each provider divides class levels, how often LINC classes are offered and the time it takes to finish levels at specific service provider locations. (The features of the three programs are summarized in Table 1 
in Appendix I).

First, the Toronto Catholic District School Board (TCDSB) has three LINC locations in the Scarborough area: Aldebrain, MaryWard and Victoria Park and each location is unique in terms of class times and levels available. MaryWard is the largest service provider offering classes at six levels (1-6). These classes combine levels: 1-2, 3-4 and 5-6. Literacy classes are only offered during evenings and weekends and they do not have a level 7. Training at levels 6-7 started in 2006 and enrollment is much lower at these levels (TCDSB 2011). According to the Scarborough locations and classes timetable (TCDSB 2011), LINC classes, levels 1-4 at MaryWard run from 9-2:30 (27.5 hours). As previously discussed, it takes approximately 1,393 hours to finish LINC 1-4. Thus, at Maryward, Monday to Friday it would take approximately 51 weeks ( 1 year) to finish these levels. However, if newcomers are working during the day, classes are available on a part-time basis: Tuesdays and Thursday evenings 6:30-9 (5 hours). It would take a newcomer 278 weeks (over 5 years) to finish levels 1-4 if they take night classes. Finally, if newcomers are enrolled in Saturday classes 9:30-12:30 ( 3 hours) due to other responsibilities weekdays and evenings, it would take 464 weeks ( 8.9 years) to finish levels 1-4.

This example assumes that learners are starting at LINC level 1 and as CIC demonstrates the majority of learners are placed in levels 2 or 3 . However, the important aspect of this example is that most newcomers have work and family responsibilities. Thus, it takes an incredible amount of time to learn a new language., MaryWard is the largest SPO for TCDSB and the other two TCDSB locations do not 
offer evening or weekend classes. Hence, language learning becomes even more difficult and time constraining.

In terms of constraints, the smaller service providers are not able to offer the amount of classes that the larger providers such as TCDSB can offer. For example, The Polycultural Immigrant \& Community Services has two locations in Scarborough: Eglinton and Midland. The Eglinton location offers classes for levels Literacy-7 and the Midland location offers classes for levels 1-5 (Polycultural 2011). These classes are also split classes, a combination of two or three levels in one classroom, and are offered from 9 to 2:30 Monday to Friday. One positive aspect of the Polycultural Immigrant \& Community Services is that they offer night classes four nights a week from 6-8:30 Monday to Thursday nights. However, they do not offer weekend classes.

Finally, the third and smallest service provider considered in this discussion is the Mennonite New Life Centre in Scarborough (Mennonite 2011). They offer a literacy class on Sundays from 1-3:30, LINC level 1, Monday to Friday 9:00-11:30 and a split class of LINC levels 2-3-4, Monday to Friday from 9-2:30. Thus, if the best case scenario is the TDCSB in terms of class hour availability and levels offered, it would take a learner even longer to finish these levels and learn English to the best of their ability.

As mentioned above, learning levels are also combined at all three service providers discussed. For example, Aldebrain offers three classes, all of which are split: 1-2, 3-4 and 5-6-7. This combination of levels is the trend at all TCDSB 
locations (TCDSB 2011). To examine difficulties and possibilities with split learning levels is not only relevant but imperative for several reasons. First, split-level learning has been a concern over the years for elementary school learning. However, more often, split-level classes are designed due to enrollment numbers and done out of necessity. Considering learners have a range of abilities, teachers have been very creative over the years, separating students in terms of needs and abilities. Further, these challenges have encouraged flexibility and innovation. One could infer from the idea of split-level language learning that it has instructional challenges. This could be true but there are also positives in this learning environment. First, instructors get to know their students over a long period of time, which could potentially be trust building. Second, split-level classes could allow instructors to get to know students' strengths and weaknesses. The difficulties lie in designing lessons accessible to multiple levels. Thus, one could infer from this information that there is a need for designing lesson plans accessible to all levels and having students apply what they learn at different levels of difficulty.

If the combined classes are due to lack of enrolment and they are designed out of necessity, why do service providers have wait lists? Further, combining class levels means service providers are also increasing class sizes. Would it not be a better learning environment for the learner if class sizes were smaller? (Beder \& Medena 2001). Second, if the classes are combined out of "necessity", for whom is this a necessity? Literature suggests that multilevel classes can be problematic for instructors in terms of meeting the needs of learners (Beder \& Medena 2001). One could infer from this information that it appears to be the necessity for the service 
provider, not the instructor or the learner. This is an issue that could be researched more in depth and considered to be another problem in our federal language learning delivery. Thus, in the next section, I will discuss class size trends at service provider agencies and possible alternatives for a better learning environment.

According to $\mathrm{CIC}$, the average class size in LINC language classes is approximately 17 students (2010). However, in the three SPOs discussed here, class sizes are approximately 20-25 students (TCDSB 2011, Polycultural 2011, Mennonite 2011). These numbers are also an approximation due to continuous intake. Attention to class sizes is imperative because more students in a classroom means less individual attention. According to Hoxby (2000), smaller classrooms show higher quality instructional and emotional support. Moreover, analysis of standardized achievement test scores available from the National Assessment of Educational Progress (NAEP) shows that across districts, there is evidence to suggest that lower class size is associated with higher student performance (Hoxby 2000). Teachers also report spending more time with individual students when the number of students was reduced. These results are consistent with analysis showing smaller classrooms to be associated with higher quality instruction (Blatchford et al. 2002). Thus, smaller classrooms are more socially interactive and supportive which benefits learners. Clearly, one avenue of further inquiry is to examine how quality instruction is beneficial for not only education but economic and health factors for learners. 


\section{Discussion, Recommendations, and Conclusions}

This program analysis reveals that there is a need for language acquisition for newcomers to Canada (CIC 2010). Numerous studies have shown that knowledge of an official language has a positive effect on earnings, and that those with limited English abilities are more likely to ẹarn less, be unemployed and/or live in poverty (Creticos et al. 2011; Martinez \& Wang 2006), which results in a greater reliance on social programs (CIC 2010). The federal government facilitates the entry of newcomers into Canada and is responsible to play a role in assistance in preparation to live and work. Thus, providing LINC for eligible newcomers is an obligation of the federal government of Canada to ensure immigrants are able to fully participate in Canadian society. Consequently, LINC evaluations conducted by CIC include all of Canada. However, Toronto and specifically Scarborough are unique in terms of numbers of newcomers, numbers of language learners and numbers of immigrants. This is important in terms of language delivery and best practices in Ontario. Thus, there is a need to not only make amendments in delivery and teaching methods but also a need to consider additional language programs and service providers to aid newcomers integrate as successfully as possible.

The challenge for the LINC programs is to ensure that they are accessible to all newcomers, are flexible and achieve a high quality of service provision. Based on my analysis, I will provide tentative recommendations to enhance and improve LINC programs, premised on the four questions I posed in the beginning, while summarizing my main conclusions from the research. 
First: To what extent are the design and delivery of the program appropriate? As discussed above, the design and delivery of the LINC program position newcomers to learn basic survival English. Most learners exit the program needing further ESL education. Learners leaving LINC after level three do not have the English language abilities to enter educational institutions, the job market, or even to communicate successfully. The design of the program does not have a standardized assessment or test to go from level to level. One could infer that this may be frustrating for learners who want to have some sort of document to show their progress. Optional standardized assessment tests could also give learner's goals to achieve and employers an idea of what a learner has accomplished and what their abilities are in terms of the language benchmarks.

Second: To what extent do settlement services that offer LINC involve the most appropriate, efficient and cost-effective methods to meet their objective? As mentioned above, the YMCA is an important locale for newcomers in Scarborough. It is the first place newcomers have to contact if they wish to take classes with LINC. Thus I propose that the province of Ontario and Federal government form a partnership, to align language training for all newcomers. The Canada-Ontario Immigration Agreement (COIA) was an excellent start. However, that agreement focused primarily on occupation-specific and other higher-level language training needs.

At the Metropolis Conference 2011, Immigration: Bridging the World to Canada, held in Vancouver, experts in TESL, LINC, ESL, FSL and official language learning had the opportunity to discuss and compare second language education 
services for adult newcomers: Language Learning Services Provided to Adult Newcomers in Alberta, Ontario and Quebec (Metropolis 2011). After discussions regarding possible alternatives, the participants centered on the crucial need for information sharing at the federal, provincial, municipal and service provider levels. For example, information sharing is a means to collaborate best practices at all levels of language training and learning. Thus, I argue that information sharing is crucial and needed for learners to enhance and improve their language learning with LINC. But there remains the question of how to alter our LINC services to provide the best service possible for learners. As mentioned above, Hart \& Cumming (1997) found that the majority of learners leaving LINC level 3 are discouraged with how much they still have to learn and learners are not confident with their language ability.

Information available to all language providers regarding alternate and additional ways for language acquisition could include two key suggestions: (1) Nation-wide Distance Education made available for individuals who wish to specialize and enhance their skills. This I suggest in addition to LINC's Home Study Program that offers internet-based learning and correspondence with learners who are at an advanced LINC level and are unable for various reasons to attend classes (Kelly et al 2007). According to Kelly et al., after a search and analysis of Distance Education best practices, one website stood out above the rest: BBC English. The $\mathrm{BBC}$ website is available at no charge and provides a wide spectrum of language learning tools for learners. The site not only provides instructor mentors but also 
frequently adds new content to their site (Kelly et al. 2007). There is a blog available for both teachers and learners and learners are encouraged to participate in forums. Moreover, there is evidence on the site of learner-learner interaction, learnerinstructor interaction and learner to content interaction. Finally, the BBC website offers a variety of tools including audio, video and photos to enhance learning for different types of learners. In sum, this site would be a great tool for the Federal government and LINC to implement across Canada. It would not only benefit learners who are restricted to be at home, it would also encourage learners to interact with other learners and have fun learning. A site such as this for LINC would also potentially lower numbers in the classroom; lower numbers would benefit all participants in the learning environment.

(2) The Toronto Public Library has 101 locations in Toronto (Toronto Public Library 2011). It has infrastructure in place for learners to access computers and the internet, to locate tools for language practice, to participate in blogs designed by librarians such as New to Canada, to participate in book clubs and workshops and to access books to practice reading. Libraries are located strategically all over Toronto and access to materials such as DVDs, magazines and books is as easy as obtaining a library card. After analyzing what different libraries offer in terms of language acquisition, I suggest that libraries team up with LINC and Canadian Language Benchmarks to provide learners with a section in the library that has books labeled with the appropriate benchmark. For example, many learners want to practice reading or read for pleasure or to learn a specific skill. However, a library is daunting in terms of knowing which book is appropriate to read at the different CLB 
levels. One could infer that adults end up reading children's books. Even though reading children's books can be pleasurable, it would be beneficial for learners to be able to choose the appropriate book with interesting content at their appropriate CLB reading level.

My third question for this research was: Are there other services that would assist the integration of newcomers that are not included in the LINC program? Instead of suggesting an entirely new additional language learning services, 1 suggest (1) Information outreach strategies for newcomers to learn more about the HOST program, which is an excellent way for both families and individuals to connect with volunteers to learn more about living in Canada and to participate in conversation on a weekly basis.

The Federal government in Canada offers the HOST service to newcomers. HOST is a type of mentor program that enables newcomers to team up with trained volunteers to assist the integration of newcomers. These volunteers are not trained language instructors. However, newcomers and volunteers converse on a regular basis. Volunteers are required to donate two to four hours a week. This is an excellent opportunity for newcomers to practice their language skills in an environment other than the classroom on a one on one basis. Even though LINC and HOST are both offered by the Federal government, there is a need for a stronger connection between service providers to encourage newcomers to join HOST and to encourage volunteers to donate their time. One might infer from the HOST name that this means a Canadian volunteer hosts a newcomer in their home. This is not the case however. The HOST program is similar to Big Brothers/Big Sisters Canada. 
It is a valuable service that potentially enriches the lives of both newcomer and volunteer. HOST does not currently advertize the language practice opportunities that occur in this type of relationship (HOST 2011). Thus, I propose that LINC and HOST should have a partnership where information is available to newcomers regarding the benefits of language practice in the HOST program. Further, HOST needs to outreach to Canadian citizens to demonstrate the valuable, enriching opportunities that HOST offers. This type of relationship builds understanding and trust for both volunteer and newcomer. Finally, these valuable programs offered by the government need to join forces to successfully aid the integration of newcomers which essentially builds a better community for all members of society.

Fourth, I posed the question regarding intersectionality in TESL training and LINC service delivery. All in all, 57 percent of Scarborough residents are foreign born. Through the lens of Intersectionality theory, one can infer that new first and second generation immigrants living in Scarborough have multiple levels of subordination that intersect. As an important first step, LINC offers language learning to new immigrants. However, time, class space and combining levels are all limitations on the newcomer's ability to effectively communicate and integrate.

LINC language services need revision in order to better serve the new immigrant. First, there is a need to have a standardized TESL training program to teach instructors about learners' backgrounds, potential difficulties they face, how these difficulties intersect, and other topics such as culture shock, antidiscrimination, stress and the multitude of other difficulties individuals and families face when moving to a new country. All LINC instructors are required to have TESL 
in order to teach English as a second language in Canada and TESL training courses could be a great place to begin to train instructors to have a better understanding of their learners. Second, there is a need for all newcomers to be eligible for language learning. Having eligibility restrictions does not align with the Federal government's principles of aiding all newcomers to integrate successfully. Without proper and adequate language training and acquisition, Canada fails newcomers. Further, in terms of eligibility, newcomers who become Canadian citizens are no longer eligible for LINC language classes. This restriction again discriminates against individuals who desperately need the language acquisition to succeed in all avenues of their lives. In terms of class sizes and level blending, LINC needs to come up with a solution to change this less effective approach in service. More classes, smaller classes, and flexible hours are obvious recommendations. However, LINC could also partner with other services in order to encourage newcomers to access services that will help with language acquisition. The Public Library and Distance Education are two examples of how LINC can partner with other services, reach out to newcomers and aid the integration and settlement of newcomers in Canada.

By proposing additional language learning tools, partnerships and access to information, we are facilitating learning opportunities for individuals who have time constraints, family responsibilities and/or are attempting to find work in Canada. In sum, if LINC aims to facilitate the social, cultural and economic integration of immigrants and refugees into Canada by providing language instruction, there is a need to address and make adjustments in this service for the benefit of all people living in Canada. 
Appendix: Table 1: Comparison of (3) Service Provider Organizations

\begin{tabular}{|c|c|c|c|}
\hline & TCDSB: Maryward & $\begin{array}{l}\text { Polycultural: } \\
\text { Eglinton }\end{array}$ & Mennonite \\
\hline Class Size & $\begin{array}{l}20-25 \text { Students } \\
\text { approx. }\end{array}$ & $\begin{array}{l}20-25 \text { Students } \\
\text { approx. }\end{array}$ & $\begin{array}{l}20-25 \text { Students } \\
\text { approx. }\end{array}$ \\
\hline Class Levels \& Divisions & $\begin{array}{l}\text { Literacy and } 1-6 \\
1 / 2,3 / 4,5 / 6 \text { split } \\
\text { classes }\end{array}$ & $\begin{array}{l}\text { Literacy-7 } \\
\text { Literacy } \\
1 / 2,3 / 4 \text { and } 5 / 6 / 7 \\
\text { split }\end{array}$ & $\begin{array}{l}\text { Literacy } \\
\text { Level } 1 \\
\text { Split class } \\
2 / 3 / 4\end{array}$ \\
\hline $\begin{array}{l}\text { Class Times } \\
\text { Days }\end{array}$ & $9-2: 30$ & $9-2: 30$ & $\begin{array}{l}\text { Literacy: } \\
\text { Sunday 1-3:30, } \\
\text { Level 1: Mon- } \\
\text { Fri. 9-11:30, } \\
\text { Split level } \\
\text { 2/3/4: Mon.- } \\
\text { Fri. 9-2:30 }\end{array}$ \\
\hline $\begin{array}{l}\text { Nights } \\
\text { Weekends }\end{array}$ & $\begin{array}{l}\text { 6:30-9:30 ( } 2 \text { nights } \\
\text { per week) } \\
9: 30-12: 30\end{array}$ & $\begin{array}{l}\text { 6-8:30 ( } 4 \text { nights per } \\
\text { week) } \\
\text { No Weekend Classes }\end{array}$ & $\begin{array}{l}\text { No Evening } \\
\text { Classes } \\
\text { No Weekend } \\
\text { Classes }\end{array}$ \\
\hline $\begin{array}{l}\text { Average time to complete } \\
\text { levels (CIC: } 2011 \text { ) } \\
\text { Literacy: } 384 \text {, LINC 1: } 379 \text {; } \\
\text { LINC 2:368, LINC } 3: 337, \\
\text { LINC 4:309, LINC 5: } 310, \\
\text { LINC 6\&7: } 300\end{array}$ & $\begin{array}{l}\text { (Levels } 1-4 \text { ): } 1 \text { year } \\
\text { (Days) } \\
5 \text { years and } 41 / 2 \\
\text { months (Nights) } \\
8 \text { years and } 7 \text { months } \\
\text { (Weekends) }\end{array}$ & $\begin{array}{l}\text { (Levels 1-4): } 1 \text { year } \\
\text { (Days) } \\
2 \text { years and } 8 \\
\text { months (Nights) } \\
\text { No weekend classes }\end{array}$ & $\begin{array}{l}\text { Literacy: } 3 \\
\text { years, } \\
\text { Level 1: } 7.5 \\
\text { months, Split } \\
\text { level 2/3/4: } \\
9 \text { months } \\
\text { No evening or } \\
\text { weekend } \\
\text { classes }\end{array}$ \\
\hline
\end{tabular}


References

Baer, S., Keim, J. \& Nowottnick, L. (2009). Intersectionality in Gender Training. Retrieved from http://www.quing.eu/files/2009/WHY paper baerkeimnowottnick.doc

Beder, H. \& Medina, P. (2001). Classroom Dynamics in Adult Literacy Education. Rutgers University. National Center for the Study of Adult Learning and Literacy. (NCSALL).

Blatchford, P., Moriarty, V., Edmonds, S. \& Martin, C. (2000). Relationships between class size and teaching: A multimethod analysis of English infant schools. American Educational Research Journal, 39, 101-132.

Blatchford, P., Goldstein, H., Martin, C., \& Browne, W. (2002). A study of class size effects in English school reception year classes. British Educational Research Journal, 28, 171-187.

CCLCS: Canadian Centre for Language \& Cultural Studies (2011). Retrieved from www.cclcs.ca

Canadian Research Institute for the Advancement of Women (2006). Intersectional Feminist Frameworks: A Primer. Ottawa: Canadian Research Institute for the Advancement of Women.

Citizenship and Immigration Canada. (1996). Canadian Language Benchmarks: English as a second language for adults, English as a second language for literacy learners. Minister of Supply and Services Canada. 
Citizenship and Immigration Canada. (2008). Language Instruction for Newcomers to Canada-Performance results by LINC level. Retrieved from http://www.cic.gc.ca/english/resources/research/linc-results/section1.asp

Citizenship and Immigration Canada. (2008). Language Instruction for Newcomers to Canada-Performance results by LINC level. Retrieved from http://www.cic.gc.ca/english/resources/research/linc-results/section2.asp

Citizenship and Immigration Canada. (2008). Language Instruction for Newcomers to Canada-Performance results by LINC level. Retrieved from http://www.cic.gc.ca/english/resources/research/linc-results/section3.asp

Citizenship and Immigration Canada. (2008). Language Instruction for Newcomers to Canada-Performance results by LINC level. Retrieved from http://www.cic.gc.ca/english/resources/research/linc-results/section4.asp

Citizenship and Immigration Canada (2008). Language Instruction for Newcomers to Canada-Performance results by LINC level . Retrieved from. www.cic.gc.ca/english/resources/research/linc-results/summary.asp

Citizenship and Immigration Canada. (2009). Discover Canada: The Rights and Responsibilities of Citizenship. Minister of Public Works and Government Services Canada.

Citizenship and Immigration Canada (2010). Evaluation of the Language Instruction for Newcomers to Canada (LINC) Program. Retrieved from www.cic.gc.ca/english/resources/evaluation/linc/2010/relevance.asp

Citizenship and Immigration Canada (2010). Evaluation of the Language Instruction 
for Newcomers to Canada (LINC) Program. Retrieved from www.cic.gc.ca/english/resources/evaluation/linc/2010/impact.asp

Citizenship and Immigration Canada (2010). Evaluation of the Language Instruction for Newcomers to Canada (LINC) Program. Retrieved from www.cic.gc.ca/english/resources/evaluation/linc/2010/management.asp

Collins, P.H. (2005). Black sexual politics: African Americans, gender, and the new racism. New York: Routledge.

Community Connection. Retrieved from http://www.211toronto.ca/splash.jsp Crenshaw, K. (1989). Demarginalizing the Intersection of Race and Sex: A Black Feminist Critique of Antidiscrimination Doctrine, Feminist Theory, and Antiracist Politics. University of Chicago Legal Forum, 14, 538-554.

Crenshaw, K. (1991). 'Mapping the Margins: Intersectionality, Identity Politics, and Violence Against Women of Color', Stanford Law Review, 43, 1241-1299. Crenshaw, K. (1993) 'Beyond Racism and Misogyny: Black Feminism and 2 Live Crew', in M. Matsuda et al. (Eds.), Words that Wound: Critical Race Theory, Assaultive Speech and the First Amendment (pp.111-132). Boulder, Colorado: Westview Press.

Creticos, P. A., Schultz, J. A., \& Beeler, A. (2011). The integration of immigrants in the workplace. Naperville, IL: Institute for Work and the Economy.

Cumming, P., Lee, E. \& Oreopoulos, D. (1989). Access: Task force on access to professions and trades in Ontario. Toronto: Ontario Ministry of Citizenship. 
Cumming, A. [1994] Does language assessment facilitate recent immigrants' participation in Canadian society? TESL Canada Journal, 11, 117-133.

Davis, K. (2008). 'Intersectionality as a buzzword: A sociology of science perspective on what makes a feminist theory successful', Feminist Theory 9[1), 67-85.

Derwing, T.M. \& Thompson, R.I. (2005). Citizenship Concepts in LINC Classrooms. TESL Canada Journal, 23(1), 44-62.

Discover Canada (2011) The Rights and Responsibilities of Citizenship: Study Guide. Her Majesty the Queen in Right of Canada, represented by the Minister of Citizenship and Immigration Canada

Findhelp Information Services (2011). Retrieved June 2, http://www.findhelp.ca/ George Brown College of Applied Arts \& Technology (2011). www.gbrownc.on.ca Grissmer, D. Flanagan, A., Kawata, J., \& Williamson, S. (2000). Improving student achievement: What NAEP scores tell us. Arlington, VA:Rand.

Hart, D. \& Cumming, A. (1997). A follow-up study of people in Ontario completing Level 3 of the Language Instruction for Newcomers to Canada (LINC) program. Report of the Ontario Region LINC Advisory Committee. Toronto, ON: Modern Language Centre, Ontario Institute for Studies in Education of the University of Toronto.

HOST (2011). Retrieved from www.cic.gc.ca/English/department/partner/host-newcomer.asp

Hoxby, C. (2000). The effects of class size on student achievement: new evidence from population variation. Quarterly Journal of Economics, 115, 1239-1285. Humber Institute of Technology and Advanced Learning (2011). Retrieved from 
www.liberalarts.humber.ca/elc/tesl.htm

James, M. (2000). Culture in ESL Instruction: An analytic framework. TESL Canada Journal, 17 (2), 36-49.

Kelly, M., Kennell, T., McBride, R., \& Sturm, M. (2007). Fast Forward: An Analysis of Online and Distance Education Language Training. New Media Language Training Inc. A Report for Citizenship and Immigration Canada.

Knudsen, Susanne V. (2006) Intersectionality - A Theoretical Inspiration in the Analysis of Minority Cultures and Identities in Textbooks. In: Caught in the Web or lost in the Textbook. Eric Bruillard, Mike Horsley, Susanne V. Knudsen and Bente Aamotsbakken.(Eds.), Paris: IUFM de Caen.

Martinez, T. E., \& Wang, T. W. (2006). Supporting English language acquisition: Opportunities for foundations to strengthen the social and economic wellbeing of immigrant families. Baltimore, MD: The Annie E. Casey Foundation. Retrieved from www.aecf.org/upload/PublicationFiles/l.pdf

Mattis, J., Grayman, N., Cowie, S., Winston, C., Watson, C., \& Jackson, D. (2008). Intersectional identities and the politics of altruistic care in a lowincome, urban community. Sex Roles, 59 (5-6), 418-428.

McGibbon E., \& Etowa J. (2007). Health Inequities \& the Social Determinants of Health: Spatial contexts of oppression. Nova Scotia Health Research Foundation Health Geomatics Conference, Halifax, NS.

McPherson, C. \& McGibbon, E. (2010) Addressing the determinants of child mental 
health: Intersectionality as a guide to primary health care renewal. Canadian Journal of Nursing Research, 42(3), 50-64.

Mennonite New Life Centre (2011). Retrieved from

http://www.mnlct.org/contact.html\#Birchmount

Meyers, M. (1993). Teaching to Diversity: Teaching and Learning in the Multi-Ethnic Classroom . Toronto: Irwin Publishing

OCASI Ontario's Council of Agencies Serving Immigrants (1993). "Immigrant Service Agencies: A Fundamental Component of Anti-Racist Social Services." Toronto: Ontario Council of Agencies Serving Immigrants.

Ontario Ministry of Finance (2011). Census Highlights 2006. Retrieved from www.fin.gov.on.ca/en/economy/demographics/census/

Pinchero, R. (1998). Integration as Ideology: Survival ESL and The Nation-State OISE: University of Toronto Press.

Polycultural Immigrant \& Community Services (2011). Retrieved from http://www.polycultural.org/index.php?option=com content\&view=article\& id=42\&Itemid $=141$

Saint Germain, Y. (2009). Toward an Enhanced Language assessment System. Metropolis Seminar on Language Acquisition and Newcomer Integration. Retrieved from http://canada.metropolis.net/events/metropolis presents/LanguageSemina r/Presentations/Saint-Germain\%20Presentation.pdf.

Statistics Canada (2006). Social Policy Analysis and Research Unit in the Social Development \& Administration Division with assistance from Toronto Public Health. Retrieved from 
http://www.toronto.ca/demographics/profiles map and index.htm

Statistics Canada (2007). Toronto, Ontario (Code535) (table). 2006 Community

Profiles. 2006 Census. Statistics Canada Catalogue no. 92-591-XWE. Ottawa.

Retrieved from

http://www12.statcan.gc.ca/census-recensement/2006/dp-pd/prof/92-

591/details/page.cfm?Lang $=\mathrm{E} \&$ Geo $1=\mathrm{CD} \&$ Code $1=3520 \&$ Geo $2=\mathrm{PR} \&$ Code $2=3$

$5 \&$ Data $=$ Count $\&$ SearchText $=$ Toronto $\&$ SearchType $=$ Begins $\&$ Search $P R=01 \& B$

$1=$ All \&GeoLevel $=$ PR\&GeoCode $=3520$

TESL Canada Federation (2011) Teaching English to speakers of other Languages

(TESL). Retrieved from www.tesl.ca

TESL Canada Federation (2011). Recognized Teacher Training Programs. Retrieved from

www.tesl.ca/Secondary Navigation/TESL Canada Recognized Teacher Trai ning Programs/Recognized Teacher Training Programs.htm

The Toronto Catholic District School Board (TCDSB) (2011) Retrieved from http://www.tcdsb.org/adulted/

Toronto Public Library (2011). Retrived from www.torontopubliclibrary.ca/

University of Toronto Woodsworth (2011). Retrieved from

www.wdw.utoronto.ca/tesol

Wilkinson, L. (2003). Advancing a Perspective on the intersections of diversity: challenges for research and social policy. Canadian Ethnic Studies 35 (3), 2634.

YMCA Young Men's Christian Association (2011). Retrieved from

www.ymcagta.org/en/newcomers/you-arrived/language/index.html 
